\section{Issues in developing a fit for purpose system for incorporating VGI in land administration in Botswana}

\begin{abstract}
Developing countries, especially in Africa are faced with a lack of formally registered land. Available limited records are outdated, inaccurate and unreliable, which makes it a challenge to properly administer and manage land and its resources. In the face of such problems, a large proportion of the population in developing countries depends on land and its resources for their sustenance. Developing countries are unable to adopt traditional land administration systems (LAS) due to their lack of capacity and financial constraints. Traditional LAS are characterised by expensive licence fees, procedures, and maintenance structures which are not feasible in developing countries. Volunteered Geographic Information (VGI) has the potential to address these challenges by providing timely, affordable, up-to-date, flexible, and fit for purpose (FFP) land information to support the limited curren systems. This paper investigates major aspects of developing a conceptual participatory framework for FFP land administration based on VGI, and conducts a case study in how the system can be applied in local processes, in the context of customary land tenure system in Botswana. The aspects were successfully implemented in the case study area to demonstrate their applicability and roles they could play in ensuring that VGI is reliable and conforms to the legal and institutional regulations of Land Boards. It has further provided an understanding of how VGI can be collected, assessed, and utilized at Land Boards to improve key land transactions on a FFP basis. Furthermore, innovative approaches to Trust and Reputation Modelling (TRM) are presented, minimising the need for ground-truthing of VGI data.
\end{abstract}

\section{Introduction}

Only 30 percent of land across developing countries is formally recorded in official records (Enemark, 2013); in rural Africa, the situation is worse with only 10 percent of land formally registered (Cheremshynskyi and Byamugisha, 2014). Available records may well be outdated, inaccurate and unreliable, which makes it a challenge to properly administer and manage land and its resources.
The reliance on traditional standards-based land administration systems (LAS), characterised by expensive licence fees, procedures, and maintenance structures is not feasible in developing countries (Enemark et al., 2014, McLaren, 2011). A lack of capacity and financial constraints are the main inhibiting factors in adopting traditional LAS used in western countries.

Volunteered Geographic Information (VGI) has the potential to address these challenges by providing timely, affordable, up-to-date, flexible, and fit for purpose (FFP) land information to support current systems. The FFP concept is supported and advanced by international agencies such as the World Bank, United Nations, Global Land Tool Network (GLTN) and International Federation of Surveyors (FIG). VGI refers to the use of tools to collect, handle and disseminate geographic information provided voluntarily by individuals without controlled processes (Goodchild, 2007). It can be used to complement and enhance official systems in terms of their currency, coverage and content.

This paper investigates major aspects of developing a conceptual framework for a FFP land administration based on VGI, and applies it in a case study in Botswana. The major aspects were identified and investigated by (Enemark et al., 2015, Zevenbergen et al., 2013) and used by (Rahmatizadeh et al., 2016a) to formulate a generic framework to serve as a basis for collecting land rights information from volunteers.

The objective of this study is to showcase the role that VGI can play in adding value and flexibility to official LAS in developing countries. Part of the context is an acknowledgement by the global community that securing land tenure for citizens in developing countries implies that less conventional forms of land tenure should be recognized and given better forms of security and protection (Payne, 2001, UN-Habitat, 2012, Zevenbergen et al., 2013). Examples of less conventional methods of recording land rights include the use of participatory approaches like VGI which can contribute to 
a FFP system with low cost and positive time efficiencies.

The process and extent to which VGI can be adopted in official systems remains a challenge which needs to be investigated. This challenge has motivated the study on how VGI can be implemented in the administration of customary land in Botswana which makes up most of the country's surface area $(71 \%)$. Currently, Land Boards (land authorities) lack proper registers of allocated land parcels. As a result, many allocated land parcels lack evidence that establishes tenure, while available land registries have outdated information (which eventually leads to an ineffective LAS).

Previous studies have lacked conceptual framework underpinnings as they only concentrated on the benefits, opportunities, challenges and potential risks of implementing a participatory LAS. The output of this paper is a conceptual participatory framework for a FFP LAS that provides a better understanding of the initiative by identifying wider aspects involved and how they can be leveraged, to provide a solid foundation that supports the adoption of VGI in official systems. For example, the aspects outline key issues that organisations should investigate and address for a successful adoption and incorporation of a flexible, inclusive and collaborative initiative capable of improving official systems in developing countries.

The structure of this paper is as follows: Section 2 presents the research background on VGI adoption in official systems in developing countries. Section 3 discusses the main aspects of a new conceptual framework in detail, using insights from previous work. Section 4 develops the conceptual framework, outlines how VGI could be incorporated into it, on a FFP basis, and introduces methods of Trust and Reputation Modelling (TRM). Section 5 presents a case study on the application of the initiative in a rural land administration environment in Botswana. Section 6 discusses implementation and formalization strategies of VGI in official systems, highlights the significance of the conceptual framework and presents future research directions. Section 7 concludes the paper.

\section{Adoption of contemporary land administration initiatives in official systems}

VGI activities have been implemented in developing countries to improve tenure security and delivery of services in informal and customary settlements. Their participatory nature has improved awareness and confidence of the public in land administration activities. Examples of information collected from these activities being used to secure land tenure can be found in rural villages in many African nations including Nigeria, Kenya, Tanzania, Ethiopia, Rwanda and Zambia (Bennett and Alemie, 2015, Enemark et al., 2014, Euwema, 2015, Odeniyi et al., 2015, Siriba and Dalyot, 2017). Authorities in these countries have adopted these initiatives to modify land registration practices and improve the lives of citizens in rural villages, especially women and children, who in the past have been side-lined by traditional systems (Quan and Payne, 2008).

Many VGI initiatives have been carried out by international organizations such as the United Nations, United States Agency for International Development (USAID), United Nations Food and Agricultural Organization (UN-FAO), World Bank, United Nations Human Settlements Programme (UNHabitat), Global Land Tool Network (GLTN), and International Federation of Surveyors (FIG). These organizations have developed land administration standards, tools and applications to facilitate the implementation and adoption of affordable, inclusive, fast and participatory LAS in many developing countries. Moreover, they continue to conduct research and implement pilot projects in these countries, and others, to improve security of tenure and service provision, mostly in rural areas. A discussion of each activity and its application areas follows in the next subsections. 


\subsection{Contemporary land administration initiatives in developing countries}

In 2012, FIG implemented a Land Administration Domain Model (LADM) an International Standardization Organization (ISO 19152:2012) standard, to regulate the design and development of LAS (Lemmen and van Oosterom, 2013). LADM presents a conceptual model that organizes concepts and relationships related to rights, responsibilities, restrictions (RRR), ownership and their associated geometric representations (Poulio et al., 2013). Since LADM is a general standard for LAS, it should cover all it aspects. However, most rights and claims in developing countries are based on socia tenures which often cannot be described relative to a single land parcel. This shortcoming has resulted in the development of a specialized specification of the standard to address different social tenures, termed the Social Tenure Domain Model (STDM) (Augustinus, 2010).

STDM was developed in 2006 by UNHabitat and GLTN, to address a gap in conventional LAS - their inability to handle customary and informal land tenures in developing countries (GLTN, 2015). STDM has been used to document tenure issues in Ethiopia, Kenya, Uganda, Zambia, Colombia and Haiti (GLTN, 2015). The first prototype of STDM was tested as a pilot project in Ethiopia in 2008, to record different tenure relationships in rural areas not accounted for in official systems (Lemmen et al., 2009). In Kenya, STDM was applied in agricultura activities for poor rural farmers to map communal water points and grazing lands to protect them from encroachment and ensure controlled grazing (GLTN, 2015).

In June 2010, The Solutions for Open Source Land Administration (SOLA) open source software was developed by UN-FAO. It was designed to support participatory activities in developing countries that could not afford the high costs of licensing commercial software products (McLaren, 2013). Recently, SOLA was implemented by UN-FAO Land Tenure Team in rural areas of Nigeria, Uganda, Ghana, Lesotho and
Cambodia to support FFP mapping concepts that facilitated the recording of land tenure rights through participatory means (Odeniyi et al., 2015, Pullar et al., 2012). The FFP concept for land administration was initiated by FIG and the World Bank in 2014 (Enemark et al., 2014). It is a participatory and inclusive initiative focused on building appropriate systems within a short period of time at affordable cost. The concept has been applied recently in Rwanda, Ethiopia, Kenya and Namibia to provide land information and security of tenure to citizens in the respective countries. Its application in these countries was mainly to fast-track the land registration processes of citizens in rural areas.

Successes of these VGI initiatives have been the engagement of local communities to map, gather demographic information and record land rights and parcel boundaries of their local areas. However, these initiatives have also encountered challenges that need to be highlighted.

\subsection{Challenges of implementing VGI initiatives}

International organisations that have implemented pilot VGI projects in the past have reported some key challenges that need to be addressed. These challenges focus on the authenticity of the information collected, legitimacy of the data collection and handling exercise, repeatability and sustainability of the systems developed, and scaleability of the initiatives. In practical terms, the key challenges include: a) lack of transparency of governments and corporations in land transactions (Johnson and Sieber, 2013), b) poor mobile phone coverage and Internet access in rural areas (Batane, 2013), c) lack of established data quality and credibility measures of contributed datasets, d) lack of knowledge of how contributed datasets can be incorporated into official databases (Johnson and Sieber, 2013, Siriba and Dalyot, 2015), e) problem of silo systems where many participatory initiatives are created by different organizations for similar purposes, and f) lack of understanding and mechanisms of how the participatory activities can be 
made sustainable for future activities (Rahmatizadeh et al., 2016b).

Institutional setups can also be barriers to adopting VGI projects in developing countries. For example, there may be a reluctance of decision makers and professionals to adopt a more flexible LAS because of resistance to change, or a reliance on colonial legacy systems. In many countries, decision makers are politically directed and when there is no political will, the possibilities of VGI acceptance in official systems are slim or non-existent. A lack of basic financial resources can also be a major constraint to adopting FFP LAS, as costs are initially high especially for preparatory implementation stages and training of coordinators and volunteers. Addressing these challenges can make cadastre and registration systems more accessible, transparent, inclusive and affordable to developing countries.

This section has discussed contemporary initiatives developed by international agencies to improve land administration processes in developing countries, by utilizing participatory means. The LADM, though not participatory, is important as the basis for other systems discussed. It embodies a relationship that citizens have with land parcels in a formal land administration setup. However, many developing countries are characterised by social tenures which LADM cannot address, hence the development of STDM. Pro-poor, participatory, affordable, and gender responsive land information systems have been developed by international agencies to address the inefficiency of conventional LAS in developing countries. Through their participatory nature, these systems have proved to be effective in improving the currency of land records, securing tenure, decreasing land conflicts, and increasing awareness of land related activities by local communities.

Generally, the need for accuracy is lower in rural areas as compared to urban areas. Hence, the FFP concept is ideal for VGI initiatives in rural areas as per the case study of this research. It is advanced here as the central tenet to establish a VGI initiative capable of adding value to LAS in developing countries. However, issues of how it can be successfully integrated with official systems remain unsolved. The outlined challenges highlight some of the core issues that need to be addressed to achieve and maintain an effective and efficient participatory system.

\section{Main aspects of VGI in land administration}

Investigations into the utilization of VGI in LAS in the case study area described later have determined that there are four major aspects which need to be addressed: a) social, b) legal, c) technical, and d) institutional (Rahmatizadeh et al., 2016a). These aspects outline key issues that organizations should investigate and address for a successful adoption and incorporation of a flexible, inclusive and collaborative initiative into official databases. They are the building blocks of a conceptual participatory framework for a FFP LAS.

\subsection{Social aspects}

The social aspects stress that understanding characteristics and behaviour of volunteers is essential to the use of VGI for authoritative purposes (Fig 1). They deal with measures that facilitate active participation, volunteer motivation and retention, volunteer profiles, conflict resolution and volunteer contribution guidelines.

Volunteer engagement strategies: A welldefined strategy defining how participants can be engaged in a participatory initiative increases the likelihood of volunteer contributions and the production of reliable datasets (Haklay et al., 2014). Once engaged, volunteers can participate as contributors, assessors, gate keepers, updaters, editors or reporters of activities taking place in their local community. 
Social Aspects of VGI

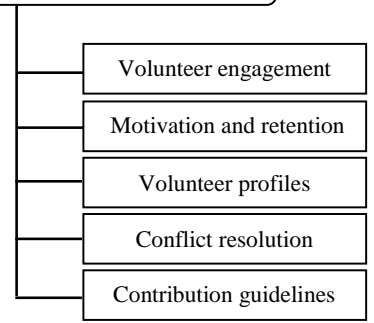

Fig 1. The social aspects of VGI in land administration

Volunteer motivation and retention: Motivations of volunteers vary greatly depending on the nature of the project. For example, volunteers may be motivated by altruism or a desire to improve the land administration and cadastral processes of their local area.

Volunteer profiles: Collecting volunteer profile information in a participatory initiative can help establish their credibility and reputation, such that the quality of their contributions can later be deduced from them (Budhathoki, 2010).

Conflict resolution: VGI can involve the handling and representation of multiple views, so there must be well defined means of determining how conflicting datasets, analyses and interpretations can be solved in the initiative.

Contribution guidelines: Most volunteers are non-experts in geographic information handling, analysis and dissemination Therefore, proper documentation of the procedures undertaken and the methods expected, can improve user experience and buy-in from all stakeholders.

\subsection{Legal aspects}

Legal issues likely to arise with the use of VGI in official systems, particularly those which have a statutory or jurisdictional role, are determined by the nature of the information and activities to be performed with it (Fig 2).

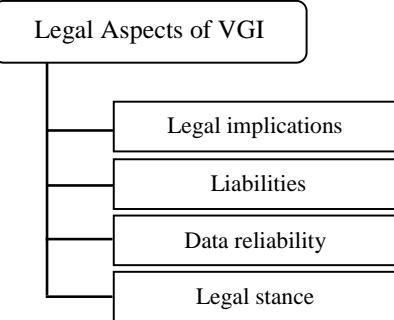

Fig 2. The legal aspects of VGI in land administration.

Legal implications of VGI: VGI quality and collection processes differ significantly from those employed for formal datasets, and constraints for its adoption in official databases can emerge. VGI is unlikely to have legal standing. Therefore, it could be adopted for improving land information with no or fewer legal consequences, especially where it does not require a high level of governmental guarantees (Bennett, 2008).

Potential liabilities: Contributors of VGI cannot be held legally responsible for their contributions. Therefore, VGI initiatives should establish procedures that address the publication of insufficient quality data through legal disclaimers or license agreements (Danay, 2010).

Data reliability: According to Scassa (2013) licence agreements in VGI platforms should specify that contributions are voluntary and that volunteers acknowledge that they have no claims to the composite work, which shall become ownership of the platform owner.

Legal stance on external data: Countries like New Zealand have a legal stance that VGI should not be integrated into the fundamental cadastre, and that all information be lodged and certified by licensed cadastral surveyors (Grant et al., 2014). Developing countries with their limited resources should be open to such VGI contributions as information that can be adopted to improve official LAS.

\subsection{Technical aspects}

A sound technical environment facilitates the generation of VGI and should be implemented such that a developed system is 
easily accessible, encourages continuous participation and ensures the contribution of good quality data (Fig 3).

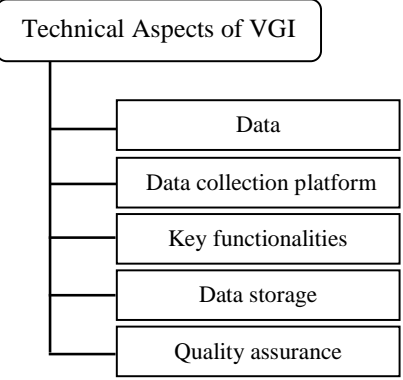

Fig 3. The technical aspects of VGI in land administration.

Data: The FFP concept advocates the use of high-resolution satellite images to collect geospatial data, and the adoption of general boundaries mapping (Enemark et al., 2014) to address challenges of outdatedness and lack of data in official systems to meet consumer needs.

Data collection platform: Instruments like smartphones, hand-held Global Positioning Systems (GPS) units, tablets and Web maps can be used to address place-based aspects where governments impact everyday life (Drummond and French, 2008). Participatory initiatives can use these instruments to actively engage local communities to provide land information about their environments, capable of improving and updating official LAS.

Key functionalities: Functionalities that enable the creation and management of VGI, especially those which promote the capture and handling of information which is nonexistent, or excluded, in official systems, can facilitate the management of land information with a potential to add value to them (Zevenbergen et al., 2013). The main functionalities can include input (e.g. volunteer contributions), analysis (e.g. volunteer analysis of existing information), management (e.g. assessment of volunteer contributions by trusted intermediaries) and presentation (e.g. information dissemination).

Data storage: To further improve its chances for consideration in authoritative systems, VGI should be stored in database schemas compatible with official databases to allow for a seamless integration when necessary.

Quality assurance: Currently, there are no agreed-upon quality measures to filter and classify information contributed by volunteers, many of whom are nongeographic information experts. Nonetheless, establishing stable data quality measures of VGI can increase its possibility of consideration and use in official systems.

This study advocates the use of TRM which establishes a 'proxy' quality and credibility measure of VGI without reference to ground truth (Bishr and Mantelas, 2008, Kessler and de Groot, 2013, Moreri et al., 2016). It uses the 'power of the crowd' principle (Haklay, 2010) to establish the level of trust of VGI and characterize the credibility of volunteers. The rationale of the principle is that inaccuracies in contributed datasets can be identified and corrected by many participants, thus reducing errors.

\subsection{Institutional aspects}

Institutional aspects are concerned with the creation of entities to manage, structure, maintain, secure, and position geospatial data contributed by volunteers, such that it produces accurate and reliable information capable of adding value to official systems (Fig 4).

Security measures: Security and authentication measures should be put in place to prevent the misuse and abuse of the application and to improve its integrity.

Scaleability and extensibility: Most institutional departments are under-resourced (either financially, in skills competency, or understaffed). Therefore, there is a need for a low cost, scaleable and extensible system that can help governments to reach most of their citizens. 
Institutional Aspects of VGI

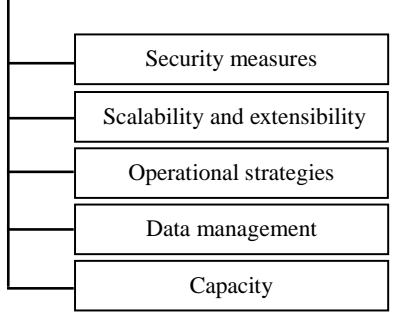

Fig 4. The institutional aspects of VGI in land administration.

Operational strategies: Well-defined operational strategies of a participatory initiative can facilitate the formulation of plans in line with national policies of the country (Enemark, 2013). Hence there is a need to establish mechanisms that can help align the VGI initiative to conform to legal and regulatory frameworks of a country of interest.

Data management: To increase the chances of volunteers contributing reliable information, VGI initiatives should allow them to contribute land information they understand and can observe, such as land parcel boundaries, road network layouts, building locations, use and ownership, vegetation extents, and drainage and water features.

Capacity: Local communities should be equipped with necessary skills and resources to interact with tools that can enable the collection and production of reliable and accurate datasets of their local area. Capacity development can be a catalyst for the longterm sustainability of the VGI initiative.

This section has discussed important aspects to be considered if VGI is to be adopted in official systems on a FFP basis Each aspect plays an important part in ensuring that VGI is accurate, reliable, trustworthy, secure, readily accessible, adequately stored and can be seamlessly incorporated into authoritative systems. The aspects discussed here, can be integrated into a conceptual framework to provide a coherent structure to facilitate the production of reliable VGI, which can be considered for use in official systems on a FFP basis.

\section{Conceptual participatory framework for FFP land administration}

This study has developed a conceptual framework, which comprises the four aspects identified to help define a participatory LAS using contemporary methods, and how all stakeholders involved can collaborate. The conceptual framework (Fig 5) highlights the fitness of VGI within government and presents broad aspects to be considered prior to its adoption in current flowlines of official systems.

The conceptual framework does not claim to address all issues regarding participatory land administration in developing countries. Rather, it highlights important linkages between the four main aspects of land administration to better articulate registering of land in rural areas using participatory means. The proposed framework is based on the participation of citizens in a semi-hybrid approach (Budhathoki, 2010), where local community members are volunteers, and experts represent supervisors and team leaders of the process. According to Basiouka et al. (2015) projects that put citizens at the centre of decision making and adopt VGI techniques can flourish with the support of experts and governmental bodies.

The conceptual participatory framework consists of six stages, with half belonging to a top-down approach and the other to a bottomup approach. The former consists of a) VGI application development, b) data handling, and c) legal stages, while the latter is made up of a) user engagement strategies, b) volunteer contributions, and c) quality assurance stages. The social aspect is confined in the bottom-up approach, while the institutional and legal aspects are in the top-down approach. The technical aspect is contained in both the approaches since it involves data handling and quality assurance measures of VGI.

The top-down approach is concerned with the initial system design processes, strategies for data handling in the initiative, and its possible uses and legal implications in official databases. A VGI initiative requires a data
Commented [KM1]: Reviewer 1, no 1: Reducing contents of chapter 3 . 
collection, analysis and management platform. It should be designed such that it is scaleable and extensible to allow for application in broader areas and for interoperability purposes. Such instances can increase its capacity to handle large amounts of datasets. Furthermore, it should be secure enough to curb abuse and mischievous volunteers, such that trust can be placed on the contributed datasets. A VGI platform should have functionalities that enable participants to contribute their own land information either in the form of digitizing land parcel boundaries or adding descriptive information about land parcels in the application Moreover, it should have a storage facility that captures all contributions for easier retrieval and manipulation. Eventually, officials are tasked with making the final decision on the quality and reliability of contributed datasets by using the aspects discussed in Section 3 and their possible application areas.

The bottom-up approach deals with volunteers, their contributions and how they can police themselves using TRM methodologies to establish the quality and reliability of datasets contributed by other participants. For volunteers to contribute to a VGI initiative, there should be well-defined strategies to motivate and ease their interaction with the type of platform adopted. Furthermore, the development of the platform should allow volunteers to freely contribute land information, edit their contributions, comment and rate the quality of contributions 


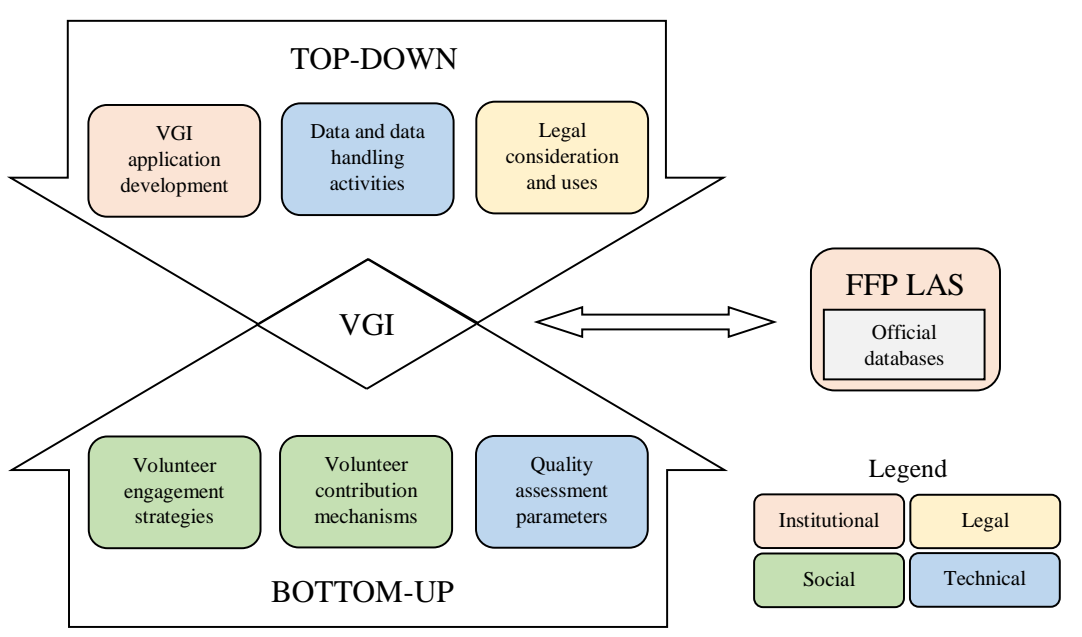

Fig 5. Conceptual participatory framework for FFP land administration.

made by other volunteers, as well as flag or report any misleading datasets.

TRM methodology facilitates volunteer assessments so that trust and confidence can be placed on contributed datasets. With TRM, participants collaborate in land administration which consequently leads to an enhancement of transparency, decreases costs (McLaren, 2011) and mitigates against the shortage of manpower common in Land Boards.

This section has discussed the conceptual participatory framework which combines the four aspects outlined in Section 3, to prove that VGI can be incorporated into official databases. VGI adoption in formal systems requires governments to embrace transparency and democratic governance since it facilitates two-way communication channels for the effective and efficient administration of land and its resources. Therefore, Fig 5 outlines a flow of events between the four aspects that include: a) a topdown approach where initial system design processes and its functionalities are discussed to enable active participation in the initiative b) a bottom-up approach centred on the volunteers to ensure that there are strategies put in place to engage, motivate, and ease their interaction with the system, as well as police themselves to ensure that reliable information is contributed, and c) another topdown approach concerned with the eventual use of VGI in official databases based on its quality, reliability and potential liabilities.

In short, the conceptual framework provides a comprehensive overview and understanding of the complexities and interconnections of the social, legal, technical and institutional aspects necessary for VGI consideration in official LAS on a FFP basis.

\section{Case Study: Applying the conceptual framework in land administration in Botswana}

The legal and institutional frameworks of Botswana recognise that non-experts can actively participate in improving LAS especially in rural areas characterized by limited resources (Ryden, 2006). Within the LAS of Botswana, the acceptance of information derived from VGI initiatives could range from tacit acceptance that there is merit in the alternative system to full government guarantee of title (Moreri et al., 2015). Rather than focusing on technical issues like standards, data integration and variable accuracies of the data, emphasis should be on the purpose and practical applications of the contributed datasets. This 
study implements VGI in a complementary and accommodative approach (McLaren, 2011, Siriba and Dalyot, 2017), and its recognition and involvement of officials, shows trust and confidence in the initiative.

\subsection{Formalization of VGI into official systems in Botswana}

A review conducted by the Auditor General of Botswana in 2008, highlighted some challenges regarding the acquisition, allocation and recording of land rights in the country (Charapua \& Barei, 2008). These include: a) lack of capacity to undertake efficient recording and management of land, b) lack of proper monitoring activities, such as development covenant checks and acquisition registers, c) poor service delivery because of a lack of a proper Land Information System (LIS) to integrate both spatial and non-spatial allocation information, and d) lack of public education, engagement and consultation in land related issues to create awareness and minimize conflicts. It is believed that these challenges can be addressed by the conceptual framework for a flexible, inclusive, participatory, efficient, and effective LAS advanced in this study.

\subsection{Data collection in the study area}

To examine more fully the role of community mapping and data collection in the Botswana context, the village of Mochudi, one of the nation's larger villages (population 44,815 in 2011) was chosen as a case study area for this research. The village has a mixture of both traditional and modern land development patterns and variable land uses which include residential, civic and community, commercial, industrial, and agriculture (commercial and subsistence farming) categories.

To assist with data capture, a Web map application was developed with ArcGIS Application Programming Interface (API) and Configurable Map Viewer (CMV) to act as a testbed for volunteers to contribute land information of their local community (Fig 6).
The application was designed such that it mimics official database schemas to enable a seamless data integration at a later stage. The database includes the following attributes: name of owner, identity number of owner, gender, occupation, plot ownership type, land parcel area, land use, current occupant, and development status.

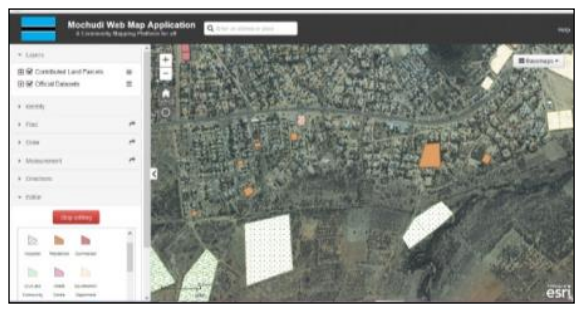

Fig 6. Mochudi VGI Web Map Application.

The current situation in the area is that land administration authorities have failed to take advantage of recent technological advancements in terms of GPS, Internet and the widespread use of smart mobile phones in the country. Currently, smart phone usage in the area is approximately three quarters $(72 \%)$ of the population (Mguni, 2017). The datasets used in this study include vector data (land parcel data, road and river networks data, contributed data by the public - attribute and spatial) and a $25 \mathrm{~cm}$ high resolution orthophoto of Mochudi.

A total of 90 volunteers were engaged for a period of 6 weeks during the southern hemisphere spring season to represent a sample of the local community. They were mandated with contributing land information of the study area using the VGI web map application. The objective of the activity was for each volunteer to digitize and annotate 12 land parcels of different land uses in the study area, which was divided into 6 different blocks. Each block consisted of 30 land parcels of varying land uses (industrial, commercial, residential, civic and community, parastatal/government department, and agriculture). For easier 
identification, land parcel centroids were predefined with red push pins, to allow for digitization and classification. To obtain multiple records, each land parcel was digitized a minimum of six times by volunteers whose coordinates were later averaged to form a single land parcel. Datasets were collected from volunteers through a digitization and annotation process. Land parcels of different land uses in the orthophoto were marked with red push pins for volunteers to digitize from the Web map application and provide descriptive information about them using their local knowledge. The quality of the data contributed was later determined using the robust TRM proposed in this study.

\subsection{VGI quality determination using TRM}

This study proposes TRM to establish the 'proxy' quality of VGI and credibility of volunteers to improve its consideration in official systems (Moreri et al., 2016). The methodology can establish a 'proxy' quality and credibility measure of VGI without the characteristic reference to ground truth, which is typical of most quality assessments. TRM uses the 'power of the crowd' principle (Haklay et al. 2010) to establish the level of trust of VGI and categorise the credibility of volunteers. It consists of four data quality indicators which include: a) thematic accuracy, b) semantic accuracy, c) volunteer credibility and d) positional accuracy measures.

An agreement measure, Fleiss Kappa, was used for thematic accuracy determination to assess the extent to which trusted intermediaries agreed to volunteer contributions. Fleiss Kappa is a statistical measure that computes the level of agreement between two or more participants in a data collection activity. In this instance, it was used to measure the extent to which experts agreed on contributions made by volunteers of how they correctly classified land use and development status parameters of land parcels in the study area. It is based on the Linus Law (Haklay, 2010) principle that, if more experts agree to a contribution, it can be regarded as true where ground datasets do not exist for comparisons. Table 1 shows thematic accuracy measures of contributed datasets and the extent to which experts agreed on volunteer contributions: a high degree of agreement indicates that trust and confidence can be placed on volunteer contributions.

The degrees of agreement of experts who assessed citizens' interpretation of different land uses and residential land parcels' development status were 0.78 and 0.65 , respectively. Thus a 'substantial' (Landis and Koch, 1977) number of experts agreed that the land parcels investigated had been correctly classified by the participants. An acceptable level of Kappa is achieved when the degree of agreement is either 'moderate' (0.41 - 0.60) or above (Landis and Koch, 1977). The values obtained with this agreement measure are acceptable and comparable to VGI quality determination studies conducted in two different regions in Germany (Arsanjani et al., 2013, Dorn et al., 2015). A high degree of agreement was expected since TRM stresses that the Linus Law principle can be utilized to establish 'proxy' quality measures of VGI quality, where ground truth is non-existent. Moreover, the local knowledge that participants have of their local area means that they are likely to be familiar with their environment, thus agree on most contributions from their peers.

TRM through Human Computation (HC) methods has demonstrated that the semantic heterogeneity common in VGI can improve the quality of VGI by aggregating contents with similar lexical terms (Table 2). Human Computation is a technique whereby some computational processes are 'outsourced' to humans (Celino, 2013). In HC, a computer asks an individual or a group of people to solve a problem, then interprets it by integrating their solutions: in VGI this can consolidate datasets contributed by different 
Table 1. Thematic accuracy determination of contributed datasets.

\begin{tabular}{lllllllll}
\hline Parameter & \multicolumn{4}{c}{ Kappa Measures for each Block } & & $\begin{array}{l}\text { Average } \\
\text { Kappa }\end{array}$ & $\begin{array}{l}\text { Agreement } \\
\text { level }\end{array}$ \\
\hline & Blk 1 & Blk 2 & Blk 3 & Blk 4 & Blk 5 & Blk 6 & & \\
\hline Land use & 0.796 & 0.795 & 0.703 & 0.813 & 0.820 & 0.750 & 0.780 & Substantial \\
Dev. status & 0.718 & 0.653 & 0.518 & 0.607 & 0.572 & 0.844 & 0.650 & Substantial \\
& & & & & & & & \\
\hline
\end{tabular}

Table 2. Consolidated output of the Human Computation approach

\begin{tabular}{|c|c|c|c|}
\hline $\begin{array}{l}\text { Land parcel } \\
\text { occupancy label }\end{array}$ & $\begin{array}{l}\text { Aggregated } \\
\text { count }\end{array}$ & Percentage (\%) & Volunteers (V) \\
\hline Mochudi bakery & 12 & 80.0 & $\begin{array}{l}\text { V1, V3, V4, V5, V7, V8, V9, V10, } \\
\text { V11, V13, V14, V15 }\end{array}$ \\
\hline $\begin{array}{l}\text { Pilane leather } \\
\text { works }\end{array}$ & 11 & 73.3 & $\begin{array}{l}\text { V1, V2, V3, V4, V5, V6, V8, V11, } \\
\text { V12, V13, V15 }\end{array}$ \\
\hline $\begin{array}{l}\text { LEA incubation } \\
\text { centre }\end{array}$ & 6 & 40.0 & V1, V4, V7, V8, V11, V14 \\
\hline Choppies & 7 & 46.7 & V1, V2, V3, V6, V9, V13, V15 \\
\hline \multicolumn{4}{|l|}{ Supermarket } \\
\hline $\begin{array}{l}\text { Pilane petrol } \\
\text { station }\end{array}$ & 12 & 80.0 & $\begin{array}{l}\text { V1, V2, V3, V4, V5, V7, V8, V9, } \\
\text { V10, V12, V13, V14 }\end{array}$ \\
\hline
\end{tabular}

volunteers (Celino, 2013, Law and von Ahn, 2011). It can increase the prospect of adopting VGI into official databases since $\mathrm{HC}$ argues that correct entity classifications can be obtained from an aggregation of contributions with similar lexical vocabulary.

Table 2 shows a sample of the consolidated output of the HC approach: each land parcel was classified by 15 different volunteers independently and the 'aggregated count' column shows the extent to which classifications with similar lexical terms were aggregated. The percentage column shows the proportions of the aggregated counts for the labelled entities. For example, the first row shows that 12 participants (from the 15 volunteers), independently labelled the land parcel of interest as 'Mochudi Bakery', making it $80 \%$ as a proportion. In this instance, semantic accuracy of the land parcel's classification is increased since the occupancy label with the highest number of similar contributions is consolidated as its final classification label.
Volunteer reputation was determined by Latent Class Analysis (LCA) methodology. It enforces the reputation element of TRM, and stresses that multiple contributions of an individual can be used to infer the quality and reliability of the data they produce. This was successfully applied in the study area, where it was identified that a total of 58 volunteers out of the $90(64.4 \%)$ belonged to a good reputation class, and only $32(35.6 \%)$ resided in a bad reputation class (Table 3).

To assess volunteer reputation, contributions from volunteers were compared against consensus-based classification values of trusted intermediaries via cross-tabulation, to represent final land parcel tags used as input for reputation computation in Mplus Statistical Analysis software (Muthén, 2004, Wickham et al., 2013). Volunteer reputation can be used to infer the quality of VGI: it can be concluded that about two thirds $(64.4 \%)$ of volunteers who participated in the land parcel classification activity can be trusted to contribute quality and reliable datasets to the VGI initiative. Volunteers with a 'good' reputation class made less errors in their land 
Table 3. The overall number of volunteers engaged and their reputations.

\begin{tabular}{lcc}
\hline Reputation Category & Number of Volunteers & Percentage of Volunteers (\%) \\
\hline Good & 58 & 64.4 \\
Bad & 32 & 35.6 \\
\hline Total & 90 & 100 \\
\hline
\end{tabular}

Table 4. RMSE computations for different land uses.

\begin{tabular}{lcc}
\hline Land Use & RMSE for Volunteers - RTK $(\mathrm{m})$ & Horizontal Accuracy Class \\
\hline Residential areas & 0.69 & $\mathrm{I}$ \\
horticultural areas & 2.05 & $\mathrm{II}$ \\
$\begin{array}{l}\text { Combined land } \\
\text { uses }\end{array}$ & 1.52 & $\mathrm{II}$ \\
\hline
\end{tabular}

parcel classification compared to those with a 'bad' reputation. The cross-tabulation results showed that a high proportion of correctly classified land parcels belonged to volunteers with a 'good' reputation.

A common scientific measure of positional accuracy, Root Mean Square Error (RMSE) (FGDC, 1998) was used to determine the amount of deviation between contributed datasets by the participants to those obtained from a Real Time Kinematic (RTK) survey process. RTK survey data was collected with a GPS unit to mimic official datasets of the study area. The data collection activity revealed that contributed geospatial datasets deviated from RTK datasets by an acceptable level, within Class II horizontal positional accuracy standards according to the Geospatial Data Specification documen (GeoManual, 2014) of Botswana (Table 4).

For village mapping activities in Botswana Class III horizontal accuracy $(2.65 \mathrm{~m}-4.59$ $\mathrm{m})$ is a minimal acceptable positional accuracy level for datasets digitized from the 1:5000 scale orthophoto (GeoManual, 2014).

Land parcels of Class II accuracy category can be used for the following mapping purposes: a) standard mapping and geographic information systems (GIS) work, b) general boundary surveys, c) land registration, d) reporting of illegal activities, e) land rights recording of monumental sites, and f) water points location determination (Moreri et al., 2016). The significance of the deviation results is that trust and confidence can be placed on datasets contributed by volunteers, for the above-mentioned purposes in official systems.

\subsection{Application of VGI in key problematic} processes at the Land Board

A scrutiny of key land transactions at the Land Board was conducted to identify problematic areas in terms of delays in providing services to customers and how VGI could be used to address these challenges. Common land transactions performed in the study area, include: a) land transfers, b) lease registrations, c) change of land use, and d) water borehole applications.

Customary law prohibits the transfer of land to other citizens without habitable developments. Therefore, land transfer processes require technical officers to conduct site visits in the presence of plot owners to physically inspect and check for developments therein. A transfer request of an undeveloped plot is usually rejected, and clients advised accordingly.

Lease registrations require a locality sketch plan, which technical officers must produce by visiting the site and surveying the plot in question and its neighbouring plots using a handheld GPS unit. Change of land use applications require site visits by land use officers to verify if the use requested is in conformance with the zoning of the area of interest. For example, an industrially zoned 
Table 5. Land Board procedures and average delays to complete customer requests.

\begin{tabular}{|c|c|c|c|}
\hline Activity & Timeline & $\begin{array}{l}\text { Number of } \\
\text { files in } 6 \\
\text { months }\end{array}$ & $\begin{array}{l}\text { Average duration to complete task and delay } \\
\text { cause }\end{array}$ \\
\hline Land transfers & 1 month & 118 & $\begin{array}{l}83 \% \text { (98) of records exceeded the } 1 \text {-month } \\
\text { period: delays caused by compliance checks } \\
\text { and technical officers to prepare locality sketch } \\
\text { plans. }\end{array}$ \\
\hline Lease registrations & 2 months & 105 & $\begin{array}{l}75 \% \text { ( } 79 \text { ) of records had site visits to survey } \\
\text { parcel boundaries done after } 3 \text { months of } \\
\text { customer application date. }\end{array}$ \\
\hline Change of land use & 2 months & 75 & $\begin{array}{l}69 \%(52) \text { of records were completed beyond } \\
\text { the allocated timeline: because of delays from } \\
\text { the technical team to provide sketch plans. }\end{array}$ \\
\hline $\begin{array}{l}\text { Water borehole } \\
\text { applications }\end{array}$ & 3 months & 50 & $\begin{array}{l}66 \%(33) \text { of records have been rejected because } \\
\text { of non-compliance with allowable distance } \\
\text { buffer limits from other neighbouring } \\
\text { boreholes }(5 \mathrm{~km} \text { buffer). About two thirds of } \\
\text { applications are completed beyond the } \\
\text { allocated timeline from customer application } \\
\text { date. }\end{array}$ \\
\hline Total records & & 348 & \\
\hline
\end{tabular}

area cannot be changed to commercial or residential or vice versa. For conservation purposes, water borehole locations are determined by a buffer distance of $5 \mathrm{~km}$ : a borehole application cannot be approved if the location applied for, has a buffer distance that is less than $5 \mathrm{~km}$ from existing nearby boreholes. This requires technical officers to visit the site and collect coordinates of the area applied for and computations conducted at the Land Board offices.

Manual files of these transactions were scrutinized for client requests received in a period of six months (January - June 2016). Emphasis was placed on the timelines achieved for each activity 1 to identify and document delays at each stage. The objective of the investigations was to understand the root causes of these problematic areas and provide recommendations on how VGI could address them. The number of files investigated and the average amount of time to process and complete the transactions are presented in Table 5.
Land transfer requests: Common challenges here are lack of habitable developments in the plot and self-extensions by owners. Plot owners usually increase their plot sizes unlawfully to later demand more financial rewards for them during land transfers.

In the past, plots were allocated with passageways between them, which facilitated the unauthorized self-extensions to occur. Allowed plot discrepancies are $+/-10 \%$ of the plot size depicted in a lease document. These transactions (both discrepancy checks and unauthorized self-extensions) can delay the land transfer process which can be addressed by the VGI application. For example, plot owners or officials could use the application to verify plot measurements and compare them with those in the lease document to verify if they differ.

This information can be used by officials to advise customers accordingly prior to visiting the site for final verifications. 118 requests were investigated for this activity, $83 \%$ (98) of records exceeded the 1-month 
service period, and the main reasons for the delays were due to compliance checks (Table 5). Considering the site visit needed for verifications, a process that took approximately a month to complete can be done within a week, with the use of the VGI application. This procedure could greatly reduce the need for site visits by technical officers, which has proved to be among the main constraints in the timely delivery of services to clients.

Lease agreement registrations: 105 records were investigated for this activity and on average, $75 \%$ (79) of records were completed after 3 months of customer application date. Just like land transfers, lease registrations require technical officers to visit the site with the plot owner to establish if there have not been any unregulated selfextensions. This process has been reported by technical officers to be time-consuming and resource wasting as appointments are never adhered to by clients, while sometimes, the Land Board fails to avail transportation for site visits. The VGI application use can eliminate the need for site visits, particularly for plots with clear boundaries as discrepancy checks can be conducted online. This procedure can shorten the time taken for applications, and thus enable the Land Board to process requests within the stipulated timeframe of two months. A process that takes close to a month to arrange and complete can be conducted successfully in a day with the use of the VGI application.

Change of land use requests: $69 \%$ (52) of change of land use records were completed beyond the allocated timeline of 2 months, with key delays being the production of locality sketch plans at the technical office. Within the 2-month timeframe allocated, sketch plans are expected to be completed in the first month of customer application However, more than half of the investigated sketch plans were completed on average after 2 months, thus delaying the application process. A change of land use request requires a land use officer to produce a land use map depicting the current use of the plot in question and those surrounding it, to establish the zoning of that area. Currently, Land Boards do not have readily available and upto-date land use maps, which could eliminate the need for site visits. Therefore, officers must visit the site with plot owners every time a change of land use request is received. This procedure depletes the already limited capacities of Land Boards. A VGI application with online land use maps can be used for land use zoning checks to expedite change of land use requests. For example, land use verifications with an up-to-date online map can be completed within a week of receipt of application compared to the current average time taken of 2 months.

Water borehole applications: $66 \%$ (33) of records examined have been rejected because of non-compliance with allowable distance buffer limits from other neighbouring boreholes. The current procedure requires residents to identify and apply for a piece of land to be used as a borehole, in areas designated for grazing purposes. Technical officers upon receipt of applications are expected to schedule a site visit with the client to collect GPS coordinates of the area requested, whose buffer distance computation is later performed at the office. The coordinates are then mapped in a borehole distribution map from a desktop computer and buffer proximity measures calculated against nearby boreholes.

The success rate of this procedure is very low (34\%), and applicants who fail are usually requested to look for alternative areas of which the same procedure described above will be repeated. A participatory Web application with a map showing existing borehole points of the study area and with functionalities like buffer and distance measures can address this challenge of borehole rejections. The public could utilize the application to search and identify suitable borehole sites, which they could apply for at the Land Board. While officers could reduce the current situation of multiple site visits as buffer computations could be conducted at the site using the offline mode capability of the application to determine a suitable borehole location that conforms to Land Board 
regulations. This could save time and resources for both the clients and officers and further increase success rates of applications. For example, an application that took about 6 months to complete, could be processed and approved within a period of 2 weeks of receipt of a client's application with the use of the VGI application. One week could be reserved for office computations, appointments scheduling and transport logistics, and the other for allocations at the site.

In this section, problematic areas of key Land Board processes where VGI could be applied to improve their delivery time and success rates of applications were presented. An examination of the processes reveals that site visits by officers to produce locality sketch plans for compliance checks are very time consuming and resource wasting requirements which could be addressed by the VGI application developed in this study. Moreover, the high failure rates of borehole applications due to non-conformance to allowed distance buffer limits could be reduced by using the VGI application, for more informed decision making.

The TRM methodology was implemented on a sample of 30 land use parcels contributed by volunteers whose 'proxy' quality was established by Fleiss Kappa. All the sample datasets were then verified to be true against land use maps of the area obtained from DSM by technical officers: this facilitated the production of locality sketch plans within the first week of receipt of customer application, thus expediting the application process. The methodology implementation brought new insights in this research, as it proved that better success rates can be achieved from datasets contributed by volunteers whose 'proxy' quality had successfully been assessed by TRM. Comparing with results from Table 5, this means that the $69 \%$ of land records completed beyond the allocated timeline can be reduced considerably with the implementation of the TRM methodology.
In short, with the acceptance of VGI in official systems, contents and currency of land records could be improved to increase the effectiveness and efficiency of officers at the Land Board, resulting in better-quality service provision to clients.

\section{Discussions and Conclusions}

The sustainability of this participatory initiative depends on the buy-in of official systems and citizens. Its success depends on the regular update, review and modification of land records and reporting of incidents as they occur within the local community by citizens. Developing countries should have a legal stance regarding the recognition and acceptance of external data in their official LAS. They should have legal documentation and specifications on how organisations can manage uncertainties and liabilities likely to be brought by external data. The formalization of VGI should focus on the value-added capabilities it can have on official systems and this could further be simplified when exact transactional areas of Land Board processes are identified and the extent to which they could improve them outlined.

The VGI application developed is based on an orthophoto which was used as a basis for data collection. The orthophoto facilitated the collection of attribute data and general boundaries of land parcels through an onscreen digitizing method. Moreover, the innovative TRM methodology was successfully applied in the study area to demonstrate that VGI can be trusted for land administration purposes particularly in rural areas characterized by ineffective LAS. For example, from the data collection activity, it was discovered that, on average, Class II positional accuracy datasets can be obtained through the digitizing method.

A scrutiny of the legal and geospatial data specifications of the study area has revealed that Class II accuracy datasets can be used for a wide variety of land administration purposes as outlined in Section 5.3. A presentation of problematic areas of key Land Board transactions was conducted to demonstrate 
potential areas where VGI could be applied to improve service delivery and increase the success rates of applications. It is anticipated that these recommendations can increase confidence in officials to recognize the potential value that VGI has in improving current land administration processes at the Land Board.

One key principle of FFP is that accuracy relates to the purpose rather than technical standards. However, computing positional accuracies using RMSE shows that the digitised land parcels conform to legal specifications of the study area. Therefore, this can improve the trust and confidence of authorities towards datasets produced from the VGI application. The conceptual framework has effectively demonstrated how VGI can be recognized as a viable source of land information capable of improving official LAS.

This paper answers the question of how VGI can be conceptualized and applied in land administration to support official databases. The conceptual framework breaks down the process of creating VGI into four connected aspects (social, legal, institutional and technical) necessary for its consideration in official systems. The aspects were successfully implemented in the case study area to demonstrate their applicability and roles they could play in ensuring that VGI is reliable and conforms to the legal and institutional regulations of Land Boards. It has further provided an understanding of how VGI can be collected, assessed, and utilized by Land Boards to improve key land transactions on a FFP basis. Future work will concentrate on investigating how the initiative can be made sustainable for developing countries, to facilitate its scaleability and extensibility to other jurisdictions.

\section{References}

ARSANJANI, J., HELBICH, M. \& BAKILLAH, M 2013. Exploiting Volunteered Geographic Information to ease Land Use Mapping of an Urban Landscape. International Archives of
Photogrammetry, Remote Sensing and Spatial Information Sciences, XL-4/W1, 51-55.

AUGUSTINUS, A. 2010. Social Tenure Domain Model: what it can mean for the land industry and the poor. Proceedings of the XXIV FIG International Congress 2010. Sydney, Australia.

BASIOUKA, S., POTSHIOU, C. \& BAKOGIANNIS, E. 2015. OpenStreetMap for cadastral purposes: an application using VGI for official processes in urban areas. Survey Review, 47, 333-341.

BATANE, T. 2013. Internet Access and Use among Young People in Botswana. International Journal of Information Technology, 3, 117-119.

BENNETT, R. 2008. Property Rights, Restrictions and Responsibilities: Their nature, design and management. PhD, Univesity of Melbourne.

BENNETT, R. \& ALEMIE, B. 2015. Fit for Purpose Land Administration: Lessons from Urban and Rural Ethiopia. Survey Review, 1, 1-10.

BISHR, M. \& MANTELAS, L. 2008. A trust and reputation model for filtering and classifying knowledge about urban growth. GeoJournal, 72, 229-237.

BUDHATHOKI, N. 2010. Participants' motivations to contribute geographic information in an online community. $\mathrm{PhD}$ Thesis, University of Illinois, Urbana-Champaign, USA.

CELINO, I. 2013. Human Computation VGI Provenance: Semantic Web-Based Representation and Publishing. IEEE Transactions on Geoscience and Remote Sensing, 51, 5137-5143.

CHEREMSHYNSKYI, M \& BYAMUGISHA, F. 2014. Developing Land Information Systems in Sub-Saharan Africa: Experiences and Lessons from Uganda and Ghana. In: BYAMUGISHA, F. (ed.) Agricultural Land Redistribution and Land Administration in Sub-Saharan Africa - Case Studies of Recent Reforms. Washington DC. USA.

DANAY, R. 2010. The Medium is Not the Message: Reconciling Reputation and Free Expression in Cases of Internet Defamation. Mc Gill Law Journal, 56, 2-38.

DONOVAN, K. 2012. Seeing Like a Slum: Towards Open, Deliberative Development. Georgetown Journal of International Affairs, 13(1), 13, 97-104.

DORN, H., TORNROS, T. \& ZIPF, A. 2015. Quality Evaluation of VGI using Authoritative Data - A Comparison with Land Use Data in Southern Germany. ISPRS International Journal of GeoInformation, 4, 1657-1671.

DRUMMOND, W. \& FRENCH, S. 2008. The future of GIS in planning. Journal of American Planning Association, 74, 161-174.

ENEMARK, S. 2013. Fit for purpose: building spatial frameworks for sustainable and transparent land governance. Annual World Bank Conference on Land and Poverty. Washington DC. USA.

ENEMARK, S., BELL, K., LEMMEN, C. \& MCLAREN, R. 2014. Fit-For-Purpose Land 
Administration. International Federation of Surveyors (FIG), 60, 1 - 39.

ENEMARK, S., MCLAREN, R. \& LEMMEN, C. 2015. Fit-for-Purpose Land Administration Guiding Principles. Nairobi, Kenya: GLTN, UNHabitat and Kadaster.

EUWEMA, J. 2015. USAID's Mobile Application to Secure Tenure (MAST) Pilot Project. Join Workshop Com3/Com7 on 'Crowdsourcing of Land Information'. Malta, Europe: FIG.

FGDC 1998. Content Standard for Digitial Geospatial Metadata. In: METADATA AD HOC WORKING GROUP, F. G. D. C. S. (ed.). 590 National Center, Reston, Virginia 20192.

GEOMANUAL 2014. Department of Surveys and Mapping Geomatics Manual. Gaborone, Botswana: Department of Surveys and Mapping.

GLTN 2015. Social Tenure Domain Model - A propoor land tool. Nairobi, Kenya: Global Too Network (GLTN) Secretariat facilitated by UNHabitat.

GOODCHILD, M. 2007. Ctizens as Sensors: The World of Volunteered Geographic Information. GeoJournal, 69, 211 - 221.

GRANT, D., DYER, M. \& HAANEN, A. 2014. A New Zealand Strategy for Cadastre 2034. FIG Congress 2014 - Engaging the Challenges - Enhancing the Relelevance. Kuala Lumpar, Malaysia: FIG.

HAKLAY, M. 2010. How Good is Volunteered Geographical Information? A Comparative Study of OpenStreetMap and Ordnance Survey Datasets. Environment and Planning B: Planning and Design, 37, 682-703.

HAKLAY, M., ANTONIOU, V., BASIOUKA, S., SODEN, R. \& MOONEY, P. 2014. Crowdsourced Geographic information use in government. In GLOBAL FACILITY FOR DISASTER REDUCTION AND RECOVERY (GFDRR), W . B. (ed.). London, UK.

JOHNSON, P. A. \& SIEBER, R. 2013. Situating the Adoption of VGI by Government. In: SUI, D. ELWOOD, S. \& GOODCHILD, M. (eds.) Crowdsourcing Geographic Knowledge: Volunteered Geographic Information (VGI) in Theory and Practice. Dordrecht, the Netherlands: Springer Science and Business Media.

KESSLER, C. \& DE GROOT, R. 2013. Trust as a Proxy Measure for the Quality of Volunteered Geographic Information in the Case of OpenStreetMap. 16th AGILE Conference on Geographic Information Science. Leuven, Belgium: Springer Lecture Notes in Geoinformation and Cartography 2013.

LAW, E. \& VON AHN, L. 2011. Human Computation, Morgan and Claypool Publishers.

LEMMEN, C. \& VAN OOSTEROM, P. 2013. The Land Administration Domain Model Standard. 5th Land Administration Domain Model Workshop. Kuala Lumpur, Malaysia.
LEMMEN, C., ZEVENBERGEN, J. \& LENGOIBONI, M. 2009. First Experience with High Resolution Imagery Based Adjudication Approach for Social Tenure Domain Model in Ethiopia. FIG World Conference on Land Governance in Support of the Millennium Development Goals - Responding to New Challenges. Washington DC. USA.

MALINOWSKI, E. \& ZIMANYI, E. 2009. Advanced Data Warehouse Design: From Conventional to Spatial and Temporal Applications, Berlin, Germany, Springer.

MCLAREN, R. 2011. Crowdsourcing Support of Land Administration - A New Collaborative Partnership between Citizens and Land Professionals. London, United Kingdom: Royal Institute of Royal Surveyors.

MCLAREN, R. 2013. Technology to Promote Transparency around Land Acquisitions. United Kingdom: The UK Department of International Development (DFID).

MGUNI, B. 2017. Information and Communications Technology Statistics Report 2016. Gaborone, Botswana.

MORERI, K., FAIRBAIRN, D. \& JAMES, P. 2015 Technological solutions for citizens' participation into cadastral mapping. 27th International Cartographic Conference. Rio de Janeiro, Brazil.

MORERI, K., FAIRBAIRN, D. \& JAMES, P. 2016. Establishing the Quality and Credibility of Volunteered Geographic Information in Land Administration Systems in Developing Countries. GIS Research UK, 24th Annual Conference. London, UK.

MUTHÉN, B 2004 Latent variable analysis: Growth mixture modeling and related techniques for longitudinal data, Newbury Park, CA, Sage Publications.

ODENIYI, P., AKINGBADE, A. \& AKANDE, A 2015. Solutions for Open Land Administration (SOLA) Software - Customization Open Source Software to Support the Systematic Land Titling Registration Pilot Project in Ondo State, Nigeria Annual World Bank Conference on Land and Poverty - Linking Land Tenure and Use for Shared Prosperity Washington DC, USA.

PAYNE, G. 2001. Urban land tenure policy options: titles or rights? Habitat International, 25, 415 429.

POULIOT, J., VASSEUR, M. \& BOUBEHREZH, A 2013. How the ISO 19152 Land Administration Domain Model performs in the comparison of cadastral systems: A case study of condominium/co-ownership in Quebec (Canada) and Alsace Moselle (France. Computers, Environment and Urban Systems, 40, 68-78.

PULLAR, N., MCDOWELL, A., SOLONOV, A. MANOKU, E. \& RIZZO, M. P. 2012. Solutions for Open Land Administration (SOLA) Software Customizing Open Source Software to Support 
Land Administration Services and Responsible Land Governance. Annual World Bank Conference on Land Poverty. The World Bank, Washington DC, USA.

QUAN, J. \& PAYNE, G. 2008. Secure Land Rights for All. In: NAUDIN, T. (ed.). Nairobi, Kenya: United Nations Human Settlements Programme (UNHABITAT).

RAHMATIZADEH, S., KALANTARI, M. RAJABIFARD, A., HO, S. \& DANESHPOUR, A. 2016b. How VGI Intersects with Land Administration. Proceedings of the 3rd Annual Conference of Research@Locate 53. Melbourne, Australia.

RAHMATIZADEH, S., RAJABIFARD, A. \& KALANTARI, M. 2016a. A conceptual framework for utilising VGI in land administration. Land Use Policy, 56, 81-89.

RYDEN, A. 2006. Specifications for Data Acquisition Topography Base Map National Mapping DSM Botswana. Department of Surveys and Mapping.

SCASSA, T. 2013. Legal issues with volunteered geographic information. Canadian Geographer 57, $1-24$

SIRIBA, D. \& DALYOT, S. 2015. Should Volunteered Geographic Information on Land Parcels be Formalized or Coexist with Formal land Administration Systems? Joint Workshop FIG Com3/Com 7 on 'Crowdsourcing of Land Information'. Malta Europe: FIG.

SIRIBA, D. \& DALYOT, S. 2017. Adoption of volunteered geographic information into the formal land administration system in Kenya. Land Use Policy, 63, 279-287.

UN-HABITAT 2012 Handling Land: Innovative Tools for Land Governance and Secure Tenure. Nairobi, Kenya: UNION Publishing Services Section.

WICKHAM, J., STEHMAN, S., GASS, L., DEWITZ, J., FRY, J. \& WADE, T. 2013. Accuracy assessment of NLCD 2006 land cover and impervious surface. Remote Sensing of Environment, 130, 294-304.

ZEVENBERGEN, J, AUGUSTINUS, C., ANTONIO, D. \& BENNETT, R. 2013. Pro-poor land administration: Principles for recording the land rights of the underrepresented. Land Use Policy, 31, 595-604. 